\title{
Fetomaternal outcome and effect of ursodeoxycholic acid in patients of obstetric cholestasis
}

\author{
Poonam Laul$^{1}$, Soma Kumari¹, Urvashi Miglani ${ }^{1 *}$, Anish Laul², \\ Shalini Gandhi ${ }^{3}$, Sanjeev Miglani ${ }^{4}$
}

\author{
${ }^{1}$ Department of Obstetrics and Gynecology, Deen dayal Upadhay Hospital, New Delhi, India \\ ${ }^{2}$ Maulana Azad Medical College, New Delhi, India \\ ${ }^{3}$ K. D. Medical College, Mathura, Uttar Pradesh, India \\ ${ }^{4}$ Sir Gangaram Hospital, New Delhi, India
}

Received: 08 June 2021

Accepted: 05 July 2021

\author{
*Correspondence: \\ Dr. Urvashi Miglani, \\ E-mail: urvashim513@gmail.com
}

Copyright: $(\odot$ the author(s), publisher and licensee Medip Academy. This is an open-access article distributed under the terms of the Creative Commons Attribution Non-Commercial License, which permits unrestricted non-commercial use, distribution, and reproduction in any medium, provided the original work is properly cited.

\begin{abstract}
Background: The objective of this study was to determine fetomaternal outcome and effect of ursodeoxycholic acid in patients of obstetric cholestasis.

Methods: This study was prospective observational descriptive study of 130 women, which was conducted in the department of obstetrics and gynaecology, Deen Dayal Upadhayay Hospital, New Delhi. Statistical analysis was performed using the $\mathrm{z}$ test when appropriate. A p value of $<0.05$ will be considered statistically significant.

Results: Spontaneous onset of labour was present in $48.5 \%$ of patients, induction was done in $31.5 \%$ of patients and in rest $20 \%$ of patients LSCS was indicated. Normal vaginal delivery occurred in 97 of 130 patients while emergency LSCS done 33 of 130 patients. Emergency LSCS was done in 16 of 33 patients due to foetal distress. Pre-term delivery and PROM occurred in $8.5 \%$ and $9.2 \%$ of patients respectively while PPH occurred in $12.3 \%$ of patients. Among the 130 cases included in present study 34 patients $(27.2 \%)$ had fetal distress, 41 patients $(31.5 \%)$ had MSL and 40 neonates $(32.0 \%)$ required NICU. 16 neonates out of $130(12.8 \%)$ had birth weight below $2.5 \mathrm{~kg}$. Apgar score was $<7$ after 5 min in 31 neonates.
\end{abstract}

Conclusions: Ursodeoxycholic acid (UDCA) is useful in relieving symptoms and decreasing the biochemical markers.

Keywords: Obstetric cholestasis, Fetomaternal outcome, Ursodeoxycholic acid

\section{INTRODUCTION}

Intrahepatic cholestasis of pregnancy is a liver disorder that occurs in $0.1-2 \%$ of pregnant women. ${ }^{1}$ The aetiology of obstetric cholestasis is undoubtedly multifactorial with genetic, environmental, and hormonal factors having important role. ${ }^{2}$ Higher incidence is noted among mothers and sisters of patients with obstetrics cholestasis. ${ }^{3}$

There is high risk of disease recurrence with subsequent pregnancies ${ }^{4}$. Increase in incidence is noted in twin pregnancy, pregnancy due to assisted reproductive techniques and in females having history of oral contraceptive use. ${ }^{5,6}$ Intrahepatic cholestasis of pregnancy
(ICP) is characterised by maternal pruritus, elevated serum transaminases and bile acids with resolution after delivery. $^{7}$

In women of ICP, there is chance of increase in caesarean delivery, induction of labour, preterm delivery, preterm rupture of membrane and postpartum haemorrhage. ${ }^{8}$ It may be associated with adverse foetal outcomes also. The risk of meconium-stained liquor, foetal asphyxia and spontaneous preterm delivery is greater in these patients.

The most effective pharmacological therapy for improvement of maternal symptoms and biochemical abnormalities is ursodeoxycholic acid (UDCA), and this 
has also been shown to reduce the adverse fetomaternal outcome. ${ }^{7,9}$ We studied for the risk factors and fetomaternal outcome in this important obstetric entity and the effect of UDCA on the obstetric results.

\section{METHODS}

This study was prospective observational descriptive study performed on 130 subjects in Deen Dayal Upadhyay Hospital Delhi over a period of one and half years.

The diagnosis of obstetric cholestasis was made by clinical symptom of pruritus without a skin rash mainly affecting extremities and worsening at night, associated with biochemical evidence of cholestasis in form of elevated transaminases (ALT and AST) with or without elevated serum bilirubin, in absence of other liver disease.

History taking, clinical examination and laboratory investigations were done to confirm the diagnosis of obstetrics cholestasis.

Other relevant investigations were done if necessary, to exclude other conditions of altered liver function tests (LFT) like hepatitis serology and ultrasound of the whole abdomen. LFT was repeated at every 1-2 weeks interval as required. Serum levels that were more than the upper limit of pregnancy specific ranges was considered positive for obstetric cholestasis.

All patients included in the study were given UDCA 300$1800 \mathrm{mg} /$ day in divided doses for the rest of the antenatal period. Insomnia and incidence of maternal outcomes were evaluated in terms of mode of delivery, pre-term labor, pre-term pre-labor rupture of membrane and post-partum hemorrhage.

Fetal outcomes analyzed were prematurity, fetal distress, meconium-stained liquor, low birth weight (less than 2.5 $\mathrm{kg}$ ), fetal growth restriction, neonatal admission and perinatal death.

The mothers were followed till 15 days after delivery to see relief of pruritus and normalization of liver function tests.

\section{RESULTS}

The study was conducted over one-and-a-half-year period and 130 subjects with pruritus without rash were included. The mean age of study subjects was $25.89 \pm 4.27$ years. 30 patients were primigravida and 100 were multigravida.52 out of 100 multigravida had history of pruritus in past pregnancy. 34 of 130 patients $(26.2 \%)$ had history of oral contraceptive pill intake and 96 of 130 patients had a family history of obstetric cholestasis. Maximum number of patients $(53.1 \%)$ were diagnosed with obstetric cholestasis between 34-36 weeks. Itching started from 3133 weeks of period of gestation in 67 out of 130 patients. In $54 \%$ of patients the itching started from the soles progressing to palms and then abdomen. 118 of 130 patients $(90.8 \%)$ had serum bilirubin level between 0.3 to $1 \mathrm{mg} \%$. 12 out of 130 had serum bilirubin between 1.1$1.4 \%$.

78 of 130 patients took treatment with UDCA for more than a week and 52 of 130 took treatment for less than a week. There was significant improvement in the AST and ALT levels after treatment with UDCA and this improvement was more pronounced in the patients who took treatment for more than a week (Figure 1). Improvement in symptoms was present in 106 of 130 patients after treatment (Figure 2).

Spontaneous onset of labour was present in $48.5 \%$ of patients. Induction was done in $31.5 \%$. 97 of 130 patients delivered vaginally while emergency LSCS was done in 33 of 130 patients. Emergency LSCS was done in 16 of 33 patients due to foetal distress. Pre-term delivery and premature rupture of membranes occurred in $8.5 \%$ and $9.2 \%$ of patients respectively while post-partum haemorrhage occurred in $12.3 \%$ of subjects (Figure 3 ).

Among the 130 cases included in present study, 34 patients (27.2\%) had foetal distress, 41 patients $(31.5 \%)$ had meconium-stained liquor and 40 neonates $(32.0 \%)$ required admission. 16 neonates out of $130(12.8 \%)$ had birth weight below $2.5 \mathrm{~kg}$. Apgar score was $<7$ after $5 \mathrm{~min}$ in 31 neonates (Figure 4).

Foetal distress was significantly higher in subjects who took UDCA for one week or less than one week ( $p$ value $<0.001$ ) (Table 1).

Still births occurred in 3 of 130 patients and 5 of the patients had intrauterine death. Intrauterine death and stillbirth occurred between 36 to 38 weeks. All these patients either reported late or were irregular in their antenatal visits.

Patients in whom improvement in serum transaminases occurred after taking treatment with UDCA also showed significant improvement in their fetomaternal outcome (Figure 5). $82.1 \%$ of patients with improvement in serum transaminases after treatment had normal vaginal delivery. The incidence of LSCS in these patients was $17.9 \%$. In patients with no improvement in serum transaminases after treatment, $58.3 \%$ of patients had LSCS.

The incidence of PROM in patients with improvement was $9.4 \%$ ( $\mathrm{p}$ value $<0.01$ ) as compared to $25 \%$ in patients without improvement. Similarly, the adverse neonatal parameters like meconium aspiration, foetal distress, admission in NICU, stillbirth and intrauterine death were significantly high in the patients in whom improvement in serum transaminases did not occur after taking treatment. Significant association between fetomaternal outcome and level of serum transaminases was present ( $p$ value $<0.001$ ). The mean SGOT and SGPT level for normal vaginal delivery was 232.35 and 221 respectively (Figure 5). 


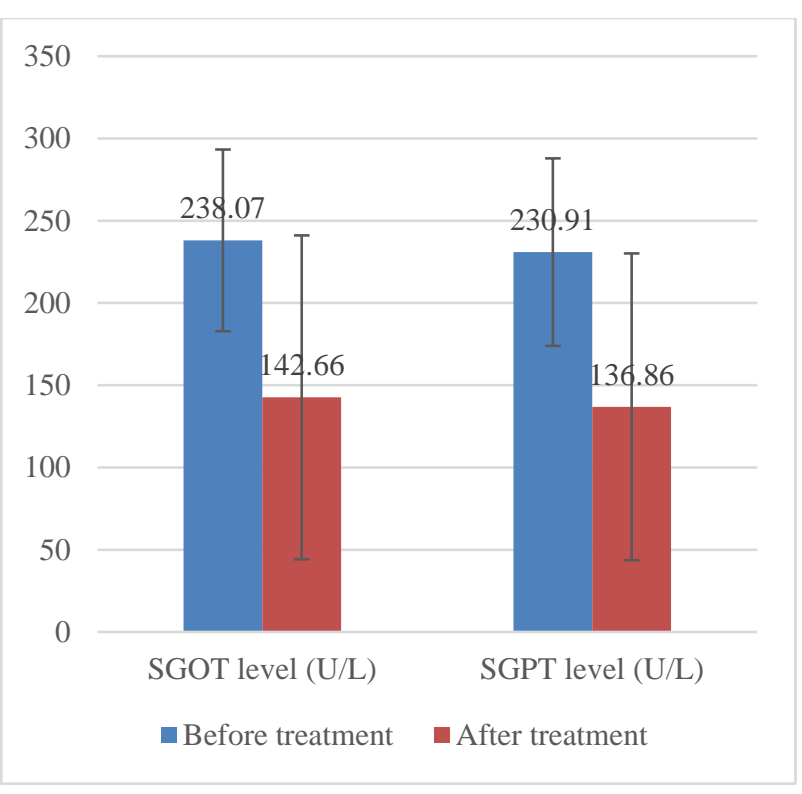

Figure 1: Comparison of SGOT and SGPT level before and after treatment in cholestasis subjects $(\mathrm{N}=\mathbf{1 3 0})$, $\mathrm{p}$ value $<\mathbf{0 . 0 0 1}$.

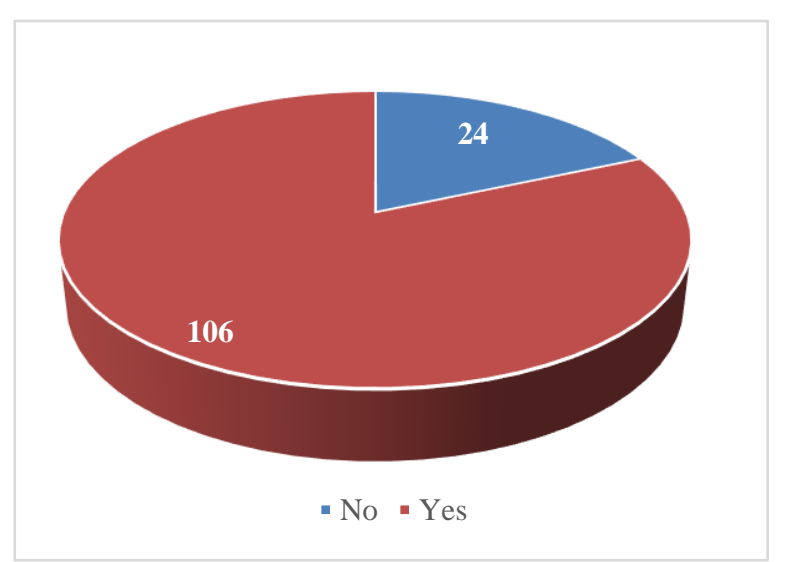

Figure 2: Improvement in symptoms after treatment in obstetric cholestasis subjects $(\mathrm{N}=130)$.

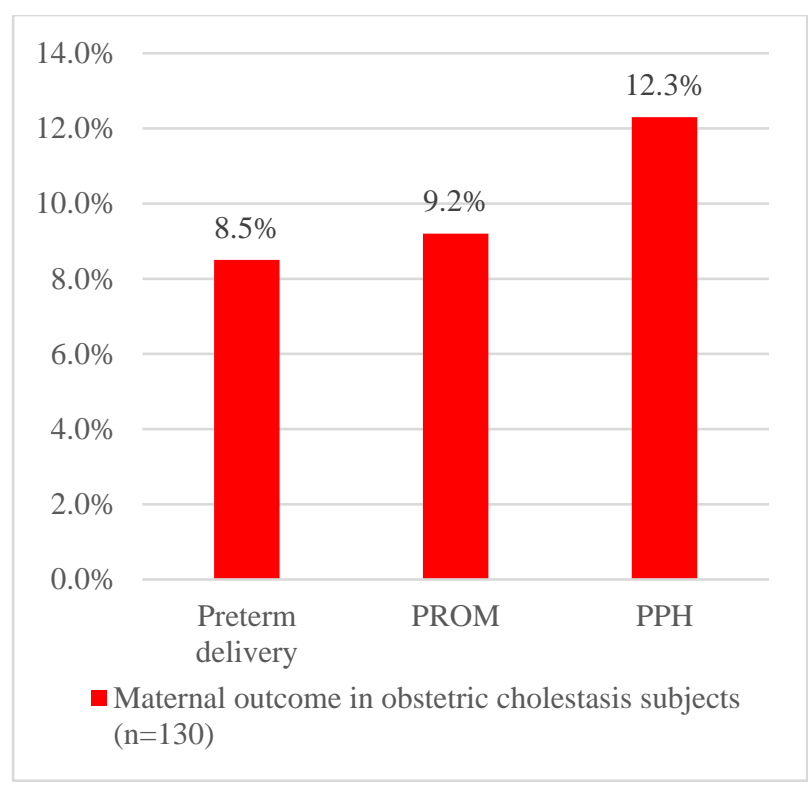

Figure 3: Maternal outcome in obstetric cholestasis subjects $(\mathbf{N}=130)$.

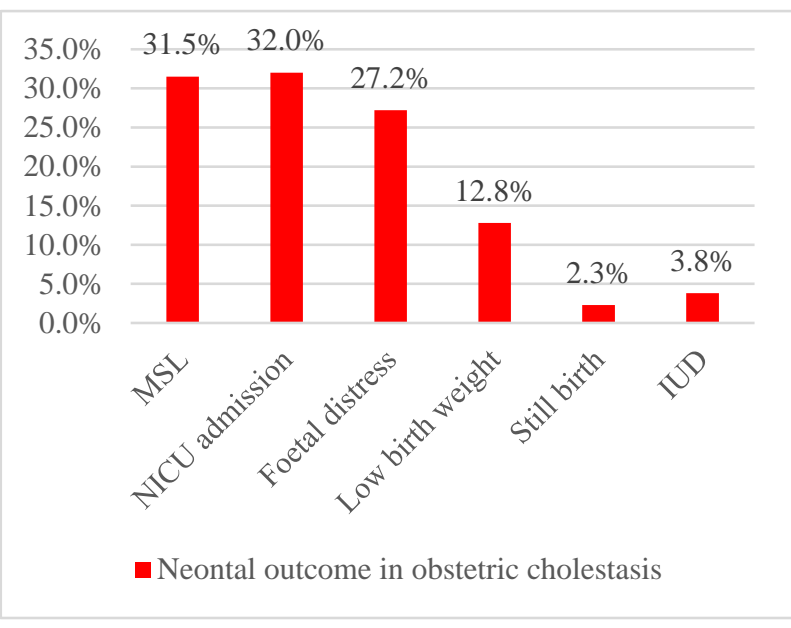

Figure 4: Neonatal outcome in obstetric cholestasis.

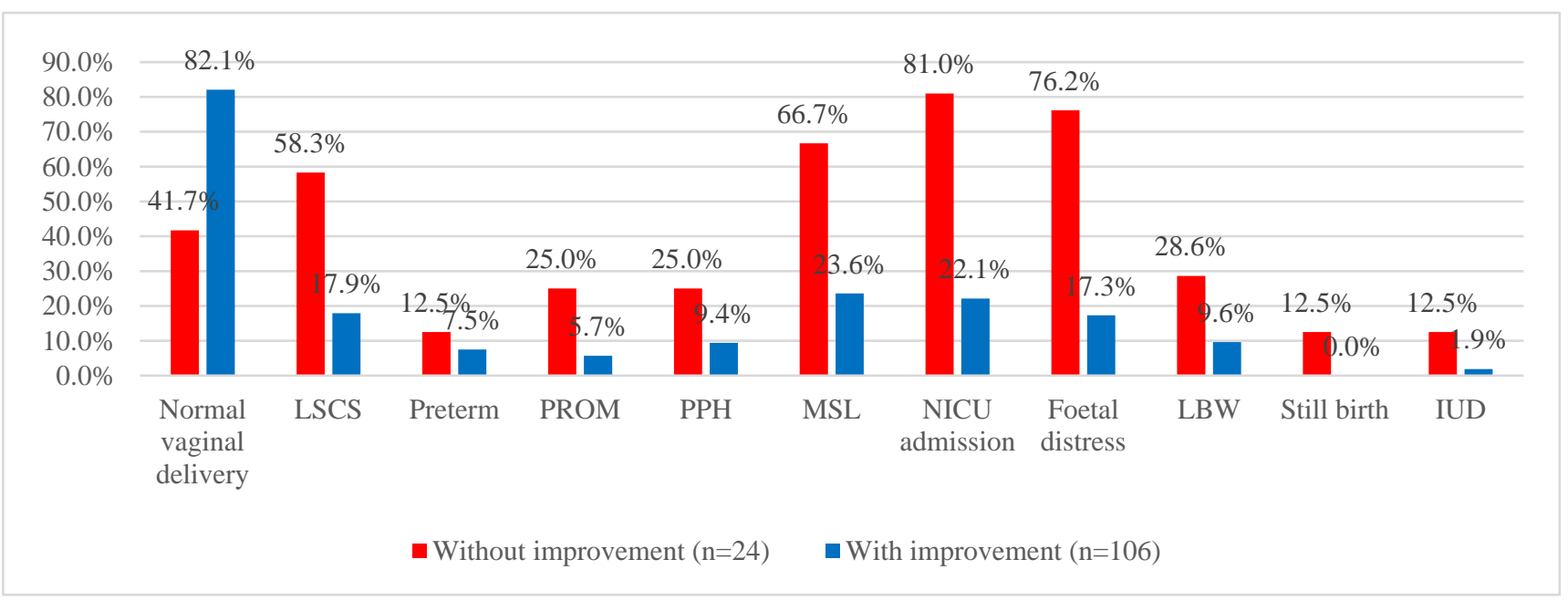

Figure 5: Association of improvement with maternal and neonatal outcome in study subject. 
Table 1: Co-relation of UDCA treatment and foetal distress.

\begin{tabular}{|lll|}
\hline $\begin{array}{l}\text { Foetal } \\
\text { distress }\end{array}$ & $\begin{array}{l}\text { UDCA treatment } \\
\leq 1 \text { week }\end{array}$ & $\begin{array}{l}\text { UDCA treatment } \\
>1 \text { week }\end{array}$ \\
\hline Present & 27 & 7 \\
\hline Absent & 18 & 73 \\
\hline
\end{tabular}

\section{DISCUSSION}

The mean age of the patients of our present study was $25.89 \pm 4.27$ years which is in line with the study by Medda et al and Ghimire et al. ${ }^{10,11}$

We observed in our study that $26.2 \%$ of women with obstetric cholestasis had history of oral contraceptives which is consistent with the study done by Williamson et al in which $27 \%$ had history of taking oral contraceptive pills. ${ }^{7}$ In our study history of pruritus in past pregnancy was present in $52 \%$ of the patients, which is comparable with that reported by Medda et al $(64.7 \%) .{ }^{9} 10-16 \%$ of patients had strong family history of obstetric cholestasis in mothers and sisters of these patients in pregnancy in the study by Turunen et al which is lower than the present study $(26 \%){ }^{3}$

In concordance with the present study, review of literature also showed high incidence of insomnia due to pruritus. Padmaja et al observed that the main symptom of ICP was pruritus which involved palms and soles in $37.8 \%$ of cases and caused disturbed sleep in all the cases. ${ }^{12}$ Ghimire et al observed that all women presented with whole-body itching. ${ }^{11}$ However, $75 \%$ of women had disturbed sleep due to severe itching. Clark et al discovered that itching worsened at night and $23.3 \%$ had associated insomnia. ${ }^{13}$

The present study pointed to a significant improvement in fetomaternal outcome with longer treatments of UDCA. Significant improvement in the serum transaminases accompanied the symptomatic relief. This has also been reflected in the study by Medda et al who found complete symptomatic improvement in $65 \%$ cases and partial response in $30 \% .{ }^{10}$ Biochemical improvement, evidenced by decreasing transaminases levels, was observed in $85 \%$ cases. The comparative evaluation of fetomaternal outcome with available literature is depicted in Table 2 and 3 shows comparable results.

Table 2: Maternal outcomes.

\begin{tabular}{|llllllll|} 
Study & $\begin{array}{l}\text { Spontaneous } \\
\text { labour }(\%)\end{array}$ & $\begin{array}{l}\text { Induction of } \\
\text { labour (\%) }\end{array}$ & LSCS & $\begin{array}{l}\text { Normal } \\
\text { vaginal } \\
\text { delivery }(\%)\end{array}$ & $\begin{array}{l}\text { Pre-term } \\
\text { delivery }(\%)\end{array}$ & $\begin{array}{l}\text { PROM } \\
(\%)\end{array}$ & $\begin{array}{l}\text { PPH } \\
(\%)\end{array}$ \\
\hline Medda et al & $\mathbf{1 0}$ & 7 & 27 & 66 & 34 & 7 & 10 \\
\hline Ghimire et al $^{\mathbf{1 1}}$ & 6 & 47.5 & 46.5 & 53.3 & 18.75 & 10 \\
\hline Hak et al $^{14}$ & 60.7 & 39.33 & & 34.22 & 10 & 7.25 \\
\hline Present study & 48 & 31.5 & 25.4 & 74.6 & 8.5 & 9.2 & 12.3 \\
\hline
\end{tabular}

Table 3: Foetal outcome.

\begin{tabular}{|c|c|c|c|c|c|c|c|}
\hline Study & MSL (\%) & $\begin{array}{l}\text { NICU } \\
\text { admission } \\
(\%)\end{array}$ & $\begin{array}{l}\text { Foetal } \\
\text { distress } \\
(\%)\end{array}$ & $\begin{array}{l}\text { Low birth } \\
\text { weight (\%) }\end{array}$ & $\begin{array}{l}\text { Apgar score at } \\
5 \mathrm{~min}<7(\%)\end{array}$ & $\begin{array}{l}\text { Still } \\
\text { birth } \\
(\%)\end{array}$ & $\begin{array}{l}\text { IUD } \\
(\%)\end{array}$ \\
\hline Medda et al $^{10}$ & 41 & 27 & 23 & 32 & & & 2 \\
\hline Hak et al ${ }^{14}$ & 38 & 24 & 9 & 15 & 8 & 1 & 4 \\
\hline Ghimire et al ${ }^{11}$ & 32.5 & 47.55 & & & 13.75 & 2.5 & 6.67 \\
\hline Present study & 31.5 & 32 & 27.2 & 16 & 24.8 & 3 & 5 \\
\hline
\end{tabular}

It was noted that stillbirth and intrauterine death mainly occurred in later weeks of the gestation. It was observed that stillbirth mainly occurred in patients who took UDCA for less than 1 week and had irregular antenatal care. It is also worth mentioning that there was negligible improvement in their symptoms and serum transaminases.

UDCA administration provides a significant improvement in maternal pruritus, biochemical abnormalities and the foetal prognosis, with no adverse effects for the mother or child. ${ }^{15}$ The results of the present study reiterate that a longer duration of UDCA resulted in a significant improvement in SGOT and SGPT levels ( $p$ value $<0.001$ ). This also translated to less operative interference
( $\mathrm{p}$ value $<0.01$ ), lesser complications and better neonatal outcomes (except low birth weight) in these patients.

Liver function tests returned to normal range and pruritus resolved by postpartum day 15 of delivery in all the subjects of our study which is consistent with most of the previous studies. ${ }^{10,16}$ To conclude, it can be stated that longer duration of treatment with UDCA is associated with a significant decrease in serum transaminases levels which also translates into better fetomaternal outcome. This highlight and reinforces the importance of early diagnosis and treatment for improvement of the outcomes. 


\section{CONCLUSION}

Early diagnosis and treatment with UDA decreases the adverse fetomaternal outcome.

\section{Funding: No funding sources}

Conflict of interest: None declared

Ethical approval: The study was approved by the Institutional Ethics Committee

\section{REFERENCES}

1. Lin $\mathrm{J}, \mathrm{Gu} \mathrm{W}, \mathrm{Hou} \mathrm{Y}$. Diagnosis and prognosis of early-onset intrahepatic cholestasis of pregnancy: a prospective study. J Matern Fetal Neonatal Med. 2019;32(6):997-1003.

2. Meng LJ, Reyes H, Palma J, Hernandez I, Ribalta J, Sjovall J. Effects of ursodeoxycholic acid on conjugated bile acids and progesterone metabolites in serum and urine of patients with intrahepatic cholestasis of pregnancy. J Hepatol. 1997;27(6):102940.

3. Turunen K, Helander K, Mattila KJ, Sumanen M. Intrahepatic cholestasis of pregnancy is common among patients' first-degree relatives. Acta Obstet Gynecol Scand. 2013;92(9):1108-10.

4. Eloranta ML, Heinonen S, Mononen T, Saarikoski S. Risk of obstetric cholestasis in sisters of index patients. Clin Genet. 2001;60(1):42-5.

5. Gonzalez MC, Reyes H, Arrese M, Figueroa D, Lorca B, Andresen M, et al. Intrahepatic cholestasis of pregnancy in twin pregnancies. J Hepatol. 1989;9(1):84-90.

6. Jie Z, Yiling D, Ling Y. Association of assisted reproductive technology with adverse pregnancy outcomes. Iran J Reprod Med. 2015;13(3):169-80.

7. Geenes V, Williamson C. Intrahepatic cholestasis of pregnancy. World J Gastroenterol. 2009;15(17):204966.
8. Shaw D, Frohlich J, Wittmann BA, Willms M. A prospective study of 18 patients with cholestasis of pregnancy. Am J Obstet Gynecol. 1982 Mar $15 ; 142(6): 621-5$.

9. Royal College of Obstetricians and Gynecologists. Obstetric Cholestasis Green top guideline, 2011. Available at: https://www.rcog.org.uk/globalassets/documents/gui delines/gtg_43. Accessed on 28 May 2021.

10. Medda S, Sengupta S, Palo U. A study of the outcome of pregnancy complicated by obstetric cholestasis. Int J Reprod Contracept Obstet and Gynecol. 2018;7(3):996-1001.

11. Ghimire SP, Ghimire A, Jha GS, Chhetry M, Kumar M. Feto-Maternal outcomes in Intrahepatic Cholestasis in Pregnancy in a Tertiary Care Centre in Eastern Nepal. J Nobel Medical College. 2016;5(1):20-5.

12. Padmaja M, Bhaskar P, Kumar GJ, Seetha R, Mahasweta C. A study of obstetric cholestasis. J Obstet Gynecol India. 2010;60(3):225-31.

13. Clark TJ, Dwarakanath L, Weaver JB. Pruritus in pregnancy and obstetric cholestasis. Hosp Med. 1999;60(4):254-60.

14. Gouri ZU, Sharma D, Berwal PK, Pandita A, Pawar S. Hearing impairment and its risk factors by newborn screening in north-western India. Matern Health Neonatol Perinatol. 2015;1:17.

15. Floreani A, Gervasi MT. New Insights on Intrahepatic Cholestasis of Pregnancy. Clin Liver Dis. 2016;20(1):177-89.

16. Rasheed S, Afghan S, Mazhar SB. Fetomaternal Outcome in Patients with Obstetric Cholestasis. Ann. Pak Inst Med Sci. 2009;5(4):211-5.

Cite this article as: Laul $\mathrm{P}$, Kumari S, Miglani U, Laul A, Gandhi S, Miglani S. Fetomaternal outcome and effect of ursodeoxycholic acid in patients of obstetric cholestasis. Int J Reprod Contracept Obstet Gynecol 2021;10:3169-73. 